\title{
INFLUÊNCIA DOS FATORES ABIÓTICOS NO FLUXO DE BIOMASSA E NA ESTRUTURA DO DOSSEL
}

\author{
INFLUENCE OF ABIOTIC FACTORS IN THE BIOMASS FLOW AND SWARD STRUCTURE
}

\author{
Vieira, M. M. M. ${ }^{1 \mathrm{a}}$ e Mochel Filho, W.J.E. ${ }^{1 \mathrm{~b}}$ \\ 'Universidade Federal do Ceará. Av. da Universidade, 2853. CP 60020. Fortaleza-CE. Brasil. \\ amarietammv@yahoo.com.br; bwilliammochel@yahoo.com.br
}

\section{PalaVRas chaVe adicionais}

Perfilhamento. Produção de forragem. Morfofisiologia do dossel. Senescência.

\section{RESUMO}

Em gramíneas tropicais, taxas de aparecimento e alongamento de folhas e a duração de vida das folhas são características influenciadas pelos fatores de crescimento como: luz, temperatura, água e fertilidade do solo que por sua vez são afetados pelo manejo adotado: altura, índice de área foliar, frequência e intensidade de pastejo, dentre outros. O entendimento das respostas destas variáveis às diferentes condições de manejo é essencial à formulação de práticas de manejo mais aperfeiçoadas, fundamentadas em conceitos morfofisiológicos. Muitas informações sobre a influência dos fatores abióticos na estrutura do dossel das gramíneas tropicais têm sido geradas no Brasil, o que muito têm contribuído para o nosso entendimento sobre o crescimento das gramíneas e a dinâmica do fluxo de biomassa do pasto. Entretanto, o uso direto destes fatores no manejo de pastagens éainda incipiente. Portanto, é apresentada e discutida a influência dos fatores abióticos no fluxo de biomassa e na estrutura do dossel, resultados gerados ao redor do mundo e algumas possibilidades de seu uso para orientação do manejo, direta ou indiretamente.

\section{SUMMARY}

In tropical grasses, rates of emergence and elongation of leaves and length of life of the leaves are influenced by the characteristics of growth factors such as light, temperature, water and soil fertility which in turn are affected by the management adopted: height, leaf area index,

\section{Additional KEYWORDS}

Tillering. Forage production. Sward morphophysiology. Senescence.

frequency and intensity of grazing, among others. An understanding of response of these variables answers to different conditions of management is essential to the formulation of improved management practices based on morphophysiological concepts. Many details about the influence of abiotic factors in the sward structure of tropical grasses have been generated in Brazil, which have contributed much to our understanding about the growth of grasses and dynamics of the biomass flow in the pasture. However, the direct use of these factors in the management of grassland is still nascent. Therefore, it is presented and discussed the influence of abiotic factors in the biomass flow and sward structure, results generated around the world and some possibilities for its use to guide the management, directly or indirectly.

\section{INTRODUÇÃO}

O Brasil possui $30 \%$ do seu território ocupado pelo setor agropecuário. Nesse contexto, as pastagens naturais ou cultivadas aparecem com excepcional destaque, ocupando cerca de 185 milhões de hectares, ou seja, $73 \%$ da área destinada ao setor (FAO, 2000). Essa fonte de alimentação adquire relevância ainda maior quando é levada em consideração sua competitividade econômica, comparada aos sistemas que adotam subprodutos agroindustriais, 
cereais e silagens como base da alimentação (Hodgson, 1990). Assim, para que seja possível explorar o potencial de produção e crescimento de uma determinada espécie forrageira é necessário conhecer a estrutura básica da planta e a maneira segundo a qual seus órgãos funcionais e seu metabolismo são afetados pelos estresses comuns a um ambiente de pastagem. Um entendimento adequado dos efeitos de variação nas condições do pasto sobre o desempenho, tanto da planta, como do animal, e da resposta de ambos ao manejo que será adotado, somente poderá ser atingido quando se conduzir estudos ba-seados no controle da estrutura do pasto.

A produtividade e a perenidade do pasto decorrem de sua capacidade de reconstituição de nova área foliar, após condições de corte ou de pastejo. Esta capacidade está intrinsecamente associada às condições ambientais, como temperatura, luminosidade, umidade e fertilidade do solo, bem como às características genéticas da planta forrageira, ao manejo da pastagem e à idade fisiológica da planta. As condições do ambiente, associadas ao estado nutricional das plantas e à idade de crescimento, são determinantes no processo de formação e manutenção dos tecidos

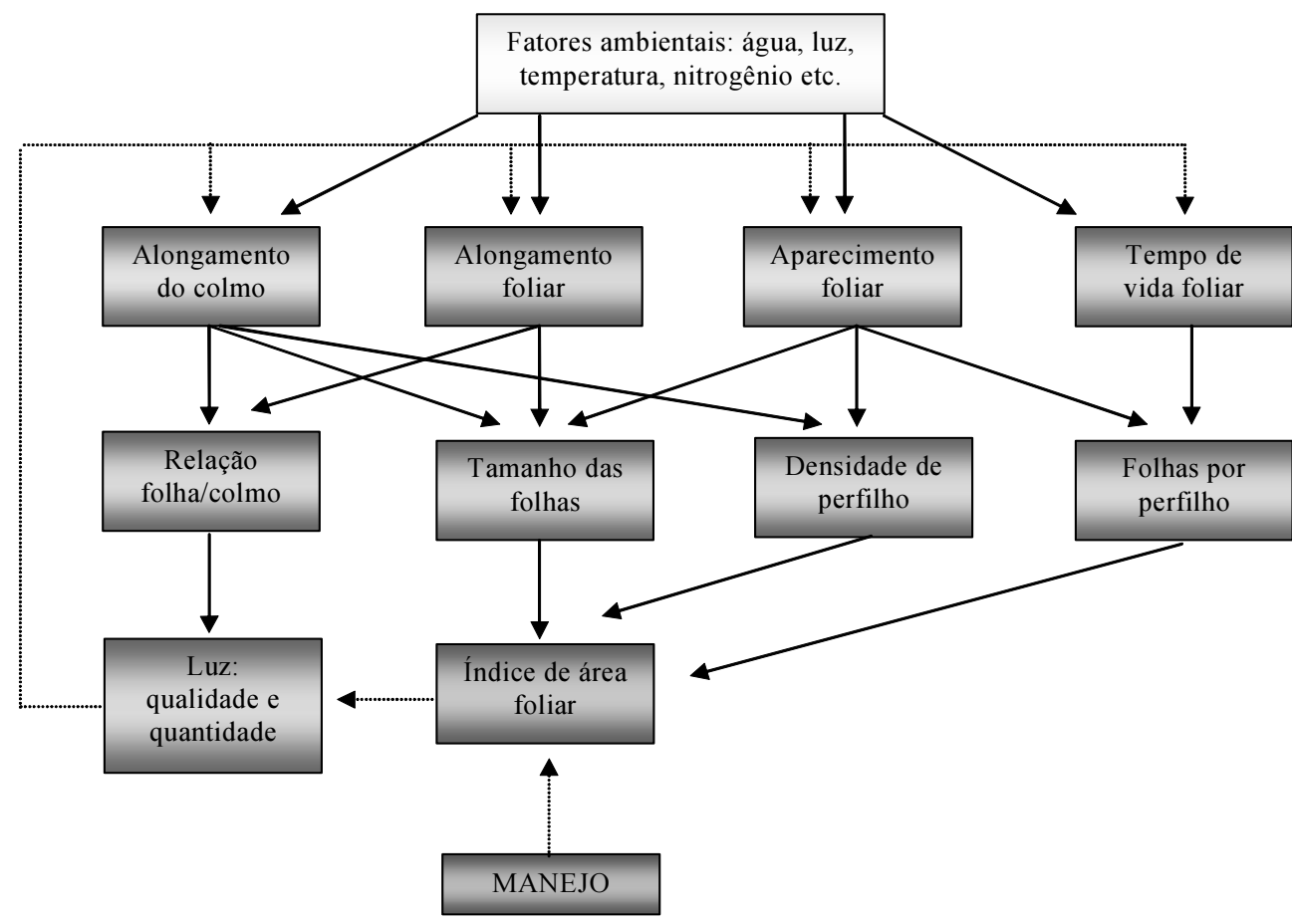

Figura 1. Relação entre as variáveis morfogênicas e as características estruturais do pasto (Chapman e Lemaire, 1993). Adaptado por Sbrissia eDa Silva (2001) e Cândido (2003). (Relationship between morphogenics variables and sward structure (Chapman and Lemaire, 1993). Adapted by Sbrissia and Da Silva (2001) and Cândido (2003)). 


\section{FATORES ABIÓTICOS E FLUXO DE BIOMASSA E ESTRUTURA DO DOSSEL}

vegetais e, consequentemente, da formação da área foliar. Sendo assim, o objetivo desta revisão é discorrer sobre a influência de fatores abióticos na estrutura do dossel (Santos Junior, 2004).

\section{MORFOFISIOLOGIADE PLANTAS FORRAGEIRAS}

A morfofisiologia é definida como a dinâmica de geração e expansão da forma e estrutura da planta no espaço (Chapman e Lemaire, 1993), é normalmente avaliada em unidades de crescimento específicas como os perfilhos no caso das gramíneas, que crescem a partir da competição pelos fatores de crescimento (Lemaire e Chapman, 1996).

A compreensão dos processos de crescimento das plantas forrageiras é o primeiro passo para a definição de estratégias racionais do manejo de pastagens. O estudo da morfofisiologia de plantas forrageiras pode contribuir bastante, à medida que fornece informações detalhadas do crescimento vegetal e se, devidamente analisados, pode propiciar o estabelecimento de estratégias de manejo que busquem maximizar a eficiência do sistema planta-animal (Stobbs, 1975). Não se busca apenas maximizar o rendimento forrageiro da pastagem, mas também conciliar esta produção com a demanda representada pelo animal em pastejo, tanto em valor nutritivo quanto em disposição ou estrutura da biomassa forrageira.

A taxa de aparecimento de folhas, além de ser uma importante característica, por representar a velocidade de formação de tecido fotossintético, também responde pelo potencial de perfilhamento da planta através do conceito de site filing (Davies, 1971; Davies e Thomas, 1983). No início da rebrotação do dossel após corte ou pastejo, a intensidade do crescimento vegetal depende, predominantemente, das taxas de alongamento e de aparecimento de folhas e perfilhos. Destes processos resulta o aumento do número de folhas vivas expandi- das do perfilho. Posteriormente, inicia-se o processo de senescência foliar das primeiras folhas expandidas, processo que se intensifica progressivamente até que as taxas de aparecimento e senescência de folhas se igualam, quando então se estabiliza o número de folhas vivas por perfilho (figura 1). Porém, o número constante de folhas vivas por perfilho, embora geneticamente determinado, varia com as condições de meio e manejo da pastagem (Lemaire e Chapman, 1996), como: as condições hídricas do solo (Van Loo, 1992), a adubação nitrogenada (Marriot, 1999; Scheneiter, 2001), além de outros fatores.

\section{FATORES ABIÓTICOS E O CRESCIMENTOVEGETAL}

A produção de matéria seca laminar é uma característica importante para o crescimento das forrageiras, visto que a lâmina foliar é o componente mais fotossinteticamente ativo do fitômero (Parsons et al., 1983).

O rendimento de massa seca de forragem ( $\mathrm{kg} / \mathrm{ha})$ está diretamente relacionado com a atividade fotossintética do dossel, já que a mesma provê a estrutura de esqueletos carbônicos que constituirão todos os compostos orgânicos da planta e toda a energia necessária para os seus processos fisiológicos. A fotossíntese, por seu turno, é regulada pela disponibilidade qualiquantitativa dos fatores abióticos, especialmente radiação solar, temperatura, água e nutrientes.

\section{RADIAÇÃO SOLAR}

A luz solar é a fonte primária de toda a energia que mantém a ecosfera do nosso planeta. Através da fotossíntese, as plantas superiores, em geral, e até mesmo algas e alguns tipos de bactérias, convertem a energia física da luz solar em energia química. Este processo é essencial para a manutenção de todas as formas de vida do planeta. Desse modo, a fotossíntese pode 
ser descrita como um processo físico-químico, mediante o qual os organismos fotossintéticos sintetizam compostos orgânicos a partir de matéria-prima inorgânica, na presença de luz solar (Larcher, 1975).

A produção forrageira se baseia na transformação de energia solar em compostos orgânicos pela fotossíntese, onde o dióxido de carbono da atmosfera é combinado com a água e convertido em carboidratos com a utilização da energia solar. Por isso, a produtividade primária de um pasto é determinada basicamente pela quantidade de carbono acumulada por unidade de área de solo, por unidade de tempo. O carbono é o principal constituinte dos tecidos vegetais e a taxa de acúmulo de biomassa de um pasto é determinada pela taxa com que o nutriente é assimilado pelas plantas (Lemaire e Chapman, 1996).

A radiação influi significativamente na taxa de alongamento das hastes. Admite-se que as maiores taxas de alongamento ocorrem sob condições de primavera e verão, quando as temperaturas máximas e mínimas atingem $33 / 28^{\circ} \mathrm{Ce} 27 / 22^{\circ} \mathrm{C}$, respectivamente. Nas condições de outono, o máximo de alongamento das hastes ocorre com temperaturas de $27 / 22^{\circ} \mathrm{C}$, havendo decréscimos se as temperaturas atingem $33 / 28^{\circ} \mathrm{C}$ (Ferraris et al., 1986).

A captação da radiação incidente pelas culturas depende do seu IAF, posição solar, geometria e tamanho da folha, ângulo de distribuição, idade, arranjo das plantas, época do ano e nebulosidade (VarletGrancher et al., 1989) e ainda da espécie cultivada e de práticas de manejo na cultura. Se o IAF aumentar muito, a produção de matéria seca não acompanhará, porque haverá grande quantidade de folhas basais sombreadas e folhas velhas que serão menos eficientes fotossinteticamente.

Além da quantidade de luz, outro aspecto importante da luz diz respeito à sua qualidade, especificamente à relação $\mathrm{V} / \mathrm{Ve}$ (vermelho/vermelho extremo) da luz inci- dente em cada camada de folhas. A ativação de gemas e a produção de novos perfilhos são dadas por esta relação $\mathrm{V} / \mathrm{Ve}$ da radiação incidente, relação essa que é reduzida à medida que se aumenta a área foliar do dossel (Matthew et al., 2000). Provavelmente, devido a isso, a produção de novos perfilhos pára antes da área foliar de equilíbrio ser alcançada.

Gautier et al. (1999) estudando duas cultivares de azevém perene (Lolium peren$n e \mathrm{~L}$.) observou que a diminuição da relação $\mathrm{V} /$ Ve reduziu o índice de perfilhamento por reduzir o site filling, ao passo que a diminuição da luz azul não teve efeito significativo no perfilhamento. As respostas de perfilhamento ao fluxo de fótons fotossintéticos e a relação $\mathrm{V} / \mathrm{Ve}$ foi semelhante nas duas cultivares selecionadas para contrastar o comprimento de folha curta e longa.

ÁGUA

A evapotranspiração potencial da pastagem geralmente excede a precipitação pluvial, ocasionando que a evapotranspiração real é aproximadamente igual à precipitação. Assim, a água é o fator isolado que mais limita a produção primária (Tieszen e Detling, 1983), principalmente o alongamento das hastes por afetar a taxa de expansão das células próximas dos meristemas.

A maior umidade do solo deve ser ajustada com o aumento do número de pastejos sobre a mesma área, pois com a aceleração do desenvolvimento da planta forrageira sob estas condições, há possibilidade de rápido desenvolvimento fisiológico da planta, o que acarreta a possibilidade de quedas nos teores de proteína bruta e elevação nos de fibra detergente neutro e fibra detergente ácido, prejudicando o consumo dos animais e reduzindo o ganho por animal. Fulkerson and Slack (1995) afirmaram que o número de folhas vivas/perfilho é definido pela espécie, mas pode-se inferir que as plantas recebendo nitrogênio e irrigação irão atingir o número máximo de folhas vivas/perfilho mais precocemente, promovendo, com isso, 
a possibilidade de desfolhações mais freqüentes, a fim de evitar perdas por senescência foliar e também em valor nutritivo.

Kneebone and Pepper (1982), em trabalho realizado sobre necessidades hídricas em três espécies de forrageiras irrigadas, concluíram que a evapotranspiração é função da demanda evaporativa da atmosfera. A evapotranspiração da cultura sob condições iguais de irrigação, expressa em percentagem de água evaporada do tanque classe A, foi de 46,48 e $64 \%$ para Cynodon dactylon, Zoysia japonica e Stemotophrum secundatum, respectivamente.

A expansão foliar é um dos processos fisiológicos mais sensíveis a deficiência hídrica. A planta cessa o alongamento de folhas e raízes muito antes dos processos de fotossíntese e divisão de células serem afetados. Por essa razão as plantas, quando não cessam a fotossíntese e a divisão de células sob deficiência hídrica, dispõem de mecanismo de crescimento compensatório quando ocorre a retomada de condições hídricas favoráveis no solo (Taiz and Zeiger, 1991).

A irregularidade da distribuição de chuvas pode ocasionar, mesmo dentro da estação chuvosa, períodos de deficiência hídrica.

Os efeitos da deficiência hídrica são difíceis de serem dissociados dos efeitos correspondentes de menor disponibilidade de nitrogênio que inevitavelmente se verificam nessas condições. Todavia, é importante considerar que os processos fisiológicos por meio dos quais essas limitações operam são diferentes. A deficiência hídrica limita a absorção de carbono pela limitação das trocas gasosas quando do fechamento dos estômatos, enquanto o nitrogênio limita a resposta fotossintética por limitação na concentração da clorofila (Lemaire, 2001). O efeito mais imediato é o fechamento dos estômatos (provocando redução na condutância estomática), embora com a intensificação do estresse outros mecanismos se desenvolvam.

A quantidade de água absorvida e transportada tem relação direta com a quantidade de energia solar interceptada. A água não pode ser considerada um recurso para o crescimento das plantas, mas sim um meio de dissipar tanto o excesso de energia solar recebida pelas folhas (evitando o dessecamento foliar) como o excesso de temperatura (Lemaire, 2001). Em algumas circunstâncias, as plantas podem se beneficiar com o sombreamento, como resultado de redução na demanda de água.

Uma leve deficiência hídrica reduz a absorção de nitrogênio e outros nutrientes absorvidos por meio do processo de fluxo de biomassa (Lemaire, 1997). Essas quantidades reduzidas de nutrientes afetam diretamente então todas as características morfogênicas e, indiretamente, as estruturais do dossel. Barreto et al. (2001) avaliando clones de capim-elefante (Pennisetum purpureum Schum), observaram que independente da cultivar, houve redução de $28 \%$ no comprimento da lâmina foliar, passando de $69,9 \mathrm{~cm}$, nas parcelas irrigadas para $50 \mathrm{~cm}$ nas que sofreram estresse hídrico, porém, a deficiência hídrica não promoveu redução no perfilhamento.

Nas regiões de clima temperado, os fatores abióticos de maior importância são luz e temperatura seguidas pela oferta de água (Van Soest, 1994). Já nos trópicos e subtrópicos, a temperatura e a deficiência hídrica são os principais fatores limitantes na produção de forragens (MacDowell, 1972).

Assim, a deficiência hídrica, com consequente redução no aporte de nitrogênio e outros nutrientes, reduz o crescimento da parte aérea, com efeito marcante na densidade populacional de perfilhos, associado à redução na assimilação de $\mathrm{CO}_{2}$ e na capacidade fotossintéticas das folhas.

Ainda que o manejo de fatores abióticos, como água e nutrientes, provoque respostas 
da pastagem consideravelmente importantes, a magnitude dessas respostas é altamente dependente do controle da desfolhação.

\section{NUTRIENTES}

A absorção de nutrientes temporariamente retidos no solo, são de responsabilidade das raízes. É importante manejar bem o solo efetuando correções e adubações para que os pecuaristas possam intensificar seus sistemas de produção animal em pastagens, via manipulação dos fatores abióticos.

Algumas características estruturais podem ser modificadas conforme a disponibilidade dos nutrientes para as plantas forrageiras. Um exemplo disto é a produção de perfilhos, que pode ser controlada pela disponibilidade principalmente de nitrogênio e, em menor escala, fósforo e potássio, podendo acentuar o aparecimento de folhas no perfilho.

Um alto padrão de aparecimento de folhas é de extrema importância para a planta, uma vez que é a folha a responsável pela interceptação de luz. O tamanho da folha é também importante, mas em algumas espécies é inversamente proporcional à taxa de aparecimento (Hume, 1991). A taxa de aparecimento de folhas varia entre e dentro de espécies. Em ambiente uniforme, a taxa de aparecimento de folhas é considerada constante, porém é amplamente influenciada por mudanças estacionais, que podem ser causadas pela disponibilidade de água e nutrientes no solo.

É importante salientar que em sistemas de pastejo, a constante remoção da área foliar previne a máxima absorção de luz por um período extenso, minimizando a competição por este recurso, mas pode diminuir o desenvolvimento das raízes, acentuando a competição por nutrientes. O contrário pode ser esperado em sistemas em que se mantém constante a área foliar.

Stobbs (1975) verificou que doses crescentes de nitrogênio mineral aplicados à Setaria anceps Stapf ex Massey cv.
Kazungula, aumentaram a produção de matéria seca total e de folhas, particularmente nas camadas superiores do dossel.

Pearse and Wilman (1984) estudando o efeito do intervalo de cortes e doses de adubação nitrogenada em azevém perene, constataram o favorecimento da produção de primórdios foliares com a aplicação de nitrogênio. Esses autores verificaram que a taxa de alongamento foliar aumentou de 4,2 para $12,1 \mathrm{~mm} /$ perfilho $\mathrm{x}$ dia, devido à adição de nitrogênio na dose de $132 \mathrm{~kg} / \mathrm{ha}$. Davies (1971) verificou que o aparecimento de folhas nessa espécie foi bastante influenciado pela dose de nitrogênio aplicado.

Segundo Mazzanti et al. (1994), quando se aumenta a dose de nitrogênio aplicada, sem o conseqüente ajuste da taxa de lotação, no caso de lotação contínua ou de diminuição no intervalo de descanso em lotação intermitente, pode-se estar permitindo aumento exagerado da senescência, acúmulo de material morto e queda na taxa de crescimento da pastagem; também ressaltaram que, em geral, ocorre diminuição na duração da vida da folha em alta disponibilidade de nitrogênio, em função da competição por luz, determinada pelo aumento da taxa de alongamento foliar e pelo maior tamanho final das folhas, assim, os resultados de decréscimo na duração da vida da folha com as doses de nitrogênio são explicados pela maior renovação de tecidos em plantas adubadas com nitrogênio.

Os primórdios foliares de azevém perene (Lolium multiflorum Lam.) quando estabelecido em solo com condição hídrica adequada e fertilização nitrogenada, passaram a se expandir rapidamente, aumentando o número de folhas vivas/perfilho (Mazzanti, 1997).

\section{TEMPERATURA}

A temperatura constitui importante fator abiótico determinante da distribuição, da adaptabilidade e da produtividade das plantas nas regiões tropicais. A adaptabilidade das plantas a altas temperaturas pode ser 


\section{FATORES ABIÓTICOS E FLUXO DE BIOMASSA E ESTRUTURA DO DOSSEL}

medida em função da capacidade destas em manter a fotossíntese líquida sob temperaturas supraótimas, ou acima do ótimo requerido para a fotossíntese líquida máxima. Por isso, a temperatura é um dos fatores ambientais que provoca efeito imediato sobre os processos bioquímicos (respiração e fotossíntese), físicos (transpiração) ou morfogênicos das plantas (Lemaire and Agnusdei, 2000).

As temperaturas durante o dia devem ser ótimas para fotossíntese e o acúmulo líquido de biomassa, enquanto à noite, as temperaturas mais baixas conservam energia por meio da redução do metabolismo respiratório.

O crescimento da planta deve-se ao aumento da temperatura que proporciona mudanças bioquímicas nas células, com elevação na taxa de crescimento foliar. Em temperaturas muito baixas, segundo Hodgson (1990), a redução no crescimento tem como causa a diminuição na assimilação de $\mathrm{CO}_{2}$. Assim, a temperatura é uma das causas da flutuação estacional da produção de biomassa, justamente, pelo comprometimento da capacidade de fotossíntese ótima da planta.

De acordo com Wilson (1982), a temperatura constitui o principal fator de ambiente que influencia na qualidade da forrageira, sob altas temperaturas as forrageiras apresentam maior proporção de parede celular e mais baixa digestibilidade, tanto da folha quanto do colmo, devido ao maior alongamento do colmo, além do aumento na lignificação da parede celular (Van Soest, 1994). A temperatura afeta a velocidade de aparecimento das folhas, pois se trata de um atributo termo-dependente.

Um aspecto importante da temperatura diz respeito à sua oscilação, tanto ao longo do dia, como ao longo do ano. Cada vez que a temperatura varia, a planta precisa se ajustar à nova temperatura. Segundo Whitheman (1980), as espécies forrageiras de clima tropical produzem muito pouco, quando expostas a temperaturas menores que $16^{\circ} \mathrm{C}$.
A temperatura sob a qual a planta se desenvolve tem maior influência sobre a taxa de alongamento de folhas do que sobre sua taxa de aparecimento (Maraschin, 1995), podendo ter sua taxa de alongamento foliar aumentada (Gastal et al., 1992). Essa alta taxa de alongamento foliar pode ocasionar folhas crescidas (no verão), devido à temperaturas mais elevadas.

Bahmani et al, 2000 observaram crescimento exponencial do perfilhamento com o aumento dos graus-dia, porém no tratamento sombreado (15\% RFA) esse crescimento foi linear, sendo que foi possível perceber uma diferença significativa entre grupos genéticos $\mathrm{x}$ tratamentos de luz $\mathrm{x}$ graus-dia $\mathrm{x}$ número de perfilhos por planta estudada (Lolium perenne L. cv. Ellet e Grasslands Ruanui).

\section{EFEITOINTEGRADODOSFATORES ABIÓTICOS SOBRE AESTRUTURA DO DOSSEL}

Um ecossistema pastagem tem por componentes bióticos as plantas, os animais e outros organismos, e como componentes abióticos o solo, os nutrientes e a atmosfera, dos quais depende o seu equilíbrio (Holechek et al., 1989). Alguns desses fatores são passíveis de controle, como o nível de nutrientes e a intensidade e a freqüência de desfolhação, e outros não, como a disponibilidade de radiação fotossinteticamente ativa, a temperatura e a precipitação.

Os fatores abióticos mais fáceis de serem controlados pelo homem são a fertilidade do solo e, em menor grau, a disponibilidade hídrica. Estes têm papel fundamental para a manutenção de pastagens produtivas e perenes, porém fatores como manejo do pastejo, lotação animal e suplementação também assumem papel fundamental na determinação da produtividade, longevidade e economicidade da atividade com a utilização intensiva das pastagens.

O conhecimento das características da 
estrutura do dossel das gramíneas forrageiras representa o ponto de partida para o entendimento básico das respostas das plantas ao corte ou pastejo. Devemos considerar os aspectos produtivos em sistemas de produção a pasto, não apenas com referências à nutrição clássica (densidade energética, teor de fibra e digestibilidade), mas sim, procurar entender os fatores de meio (estrutura da pastagem), agentes diretos, que afetam a obtenção dos nutrientes pelos animais, em tais sistemas, podendo assim, obter sucesso dentro da atividade pecuária.

Em função disto, torna-se indispensável o correto e aprofundado estudo das características estruturais de forma integrada e diferenciada para as principais gramíneas forrageiras de interesse econômico.

\section{BIBLIOGRAFIA}

Bahmani, I., Hazard, L., Varlet-Grancher, C., Betin, M., Lemaire, G., Matthew, C. and Thom, E.R. 2000. Differences in tillering of long- and shortleaved perennial ryegrass genetic lines under full light and shade treatments. Crop Sci., 40: 1095-1102.

Barreto, G.P., Lira, M.A., Santos, M.V.F. and Dubeux Junior, J.C.B. 2001. Avaliação de clones de capim-elefante (Pennisetum purpureum Schum) e de um híbrido com milheto (Pennisetum glaucum) submetidos a estresse hídrico. Parâmetros morfogênicos. Rev. Bras. Zootecn., 30: 1-6.

Cândido, M.J.D. 2003. Morfofisiologia e crescimento do dossel e desempenho animal em Panicum maximum cv. Mombaça sob lotação intermitente com três períodos de descanso. Tese (Doutorado em Zootecnia). Universidade Federal de Viçosa. Viçosa, MG. 134 pp.

Chapman, D.F. and Lemaire, G. 1993. Morphogenic and structural determinants of plant regrowth after defoliation. In: Baker, M.J. (Ed.). Grasslands for our world. SIR. Wellington. pp.55-64.

Davies, A. 1971.Changes in growth rate and morphology of perennial ryegrass swards at high and low nitrogen levels. J. Agric. Sci., 77: 123-134.

\section{CONCLUSÕES}

O potencial das pastagens será obtido através do estudo de sistemas de produção, que devem explorar a capacidade de perfilhamento da planta, e ao mesmo tempo procurar a combinação entre a quantidade de forragem e a exigência nutricional do animal. A utilização intensiva de pastagens requer uma concepção correta sobre os princípios básicos que norteiam o seu manejo. Dentro desse contexto, os fatores abióticos possuem papel fundamental para a manutenção de pastagens produtivas e perenes. Também fatores como manejo do pastejo, taxa de lotação e suplementação assumem papel fundamental na determinação da produtividade, longevidade e economicidade da atividade.

Davies, A. and Thomas, H. 1983. Rates of leaf and tiller production in young spaced perennial ryegrass plants in relation to soil-temperature and solar-radiation. Ann. Bot., 51: 591-597.

FAO. 2000. Food and Agriculture Organization of the United Nations. Disponível em: http:// apps.fao.org/. Consultado em 10-03-2008.

Ferraris, R., Mahony, M.J. and Wood, T.T. 1986. Effect of temperature and solar radiation on the development of dry matter and attributes of elephant grass (Pennisetum purpureum Schum). Aust. J. Agr. Res., 37: 621-632.

Gastal, F., Bélanger, G. and Lemaire, G. A model of the leaf extension rate of tall fescue in reponse to nitrogen and temperature. Ann. Bot., 70: 437-442.

Gautier, H., Varlet-Grancher, C. and Hazard, L. 1999. Tillering responses to the light environment and to desfolhação in populations of perennial gramínea (Lolium perenne L.) selected for contrasting leaf length. Ann. Bot., 83: 423-429.

Hodgson, J. 1990. Grazing management: science into pratice. John Wiley, Longman Scientific and Technical. New York. 203 pp.

Holechek, J.L., Pieper, R.D. and Herbel, C.H. 1989. Range management: principles and practices. Prentice-Hall, Inc. New Jersey. 501 pp. 


\section{FATORES ABIÓTICOS E FLUXO DE BIOMASSA E ESTRUTURA DO DOSSEL}

Hume, D.E. 1991. Leaf and tiller production of praire grass (Bromus willdenowwil) and two ryegrass (Lolium) species. Ann. Bot.,67: 111121.

Kneebone, W.R. and Pepper, J.L. 1982. Consumptive water use by sub-irrigated Turfgrasses under desert conditions. Agron. J., 74: 419-423.

Larcher, W. 1975. Physiological plant ecology. Spring-Verlag. Berlin. $252 \mathrm{pp}$.

Lemaire, G. 2001. Ecophysiology of grasslands: Dynamic aspescts of forage plant populations in grazed swards. In: Gomide, J.A., Mattos, W.R.S., Da Silva, S.C. (Eds.). International Grassland Congress, 19, São Pedro, Proceedings... São Pedro: FEALQ, 2001. pp. 29-37.

Lemaire, G. 1997. The physiological of grass growth under grazing: tissue turnover. In: Simpósio Internacional de Produção Animal em Pastejo. Viçosa. Anais... UFV. Viçosa. pp.117144.

Lemaire, G. and Agnusdei, M. 2000. Leaf tissue turn-over and efficiency of herbage utilization. In: Lemaire, G., Hodgson, J., Moraes, A. (Eds). Grassland ecophysiology and grazing ecology. CAB International. Wallingford. pp. 265-288.

Lemaire, G. and Chapman, D.F. 1996. Tissue flows in grazed plant communities. In: Hodgson, J., Illius, A.W. (E.E.). The ecology and management of grazing systems. CAB International. Oxon. pp.3-36.

Macdowell, F.D.H. 1972. Phototactic action spectrum for whitefly and the question of color vision. Can. Entomol., 104: 299-307.

Maraschin, G. E. 1995. Manejo de coastcross-1 sob pastejo. In: Workshop sobre o potencial forrageiro do gênero Cynodon. Anais... Embrapa. CNPGL. Juiz de Fora. pp. 93-107.

Marriot, C.A., Barthram, G.T. and Bolton, G.R. 1999. Seasonal dynamics of leaf extension and losses to senescence and herbivory in extensively managed sown ryegrass-white clover swards. J. Agr. Sci., 132: 77-89.

Matthew, C., Assuero, S.G., Black, C.K. and Hamilton, N.R.S. 2000. Tiller dynamics of grazed swards. In: Lemaire, G., Hodgson, J., Moraes, A., Carvalho, P.C. de F. and Nabinger, C. (Eds.). Grassland ecophysiology and grazing ecology. CABI Publishing. Wallingford. pp. 127-150.

Mazzanti, A. 1997. Adaptación de especies forrajeras a la defoliación. In: Simpósio sobre Avaliação de Pastagens com Animais, 1. Maringá. Anais... Maringá. pp.75-84.

Mazzanti, A., Lemaire, G. and Gastal, F. 1994. The effect of nitrogen fertilization upon the herbage production of tall fescue swards continuously grazed with sheep. 1. Herbage growth dynamics. Grass Forage Sci., 49: 111-120.

Parsons, A.J., Leafe, E.L., Collet, B. and Stiles, W.1983. The physiology of grass production under grazing. 1. Characteristics of leaf and canopy photosyntesis of continuously grazed swards. J. Appl. Ecol. 20: 117-136.

Pearse, P.J. and Wilian, D. 1984. Effects of applied nitrogen on grass leaf initiation, development and death in field swards. J. Agr. Sci.,103: 405413.

Santos Junior, J.D.G., Monteiro, F.A. and Lavres Junior, J. 2004. Análise de crescimento do capim-marandu submetido a doses de nitrogênio. Rev. Bras. Zootecn., 33 (supl. 2): 985-1991.

Sbrissia, A.F. and Da Silva, S.C. 2001. O ecossistema de pastagens e a produção animal. In: Mattos, W.R.S. (Ed.). A produção animal na visão dos brasileiros. SBZ. Piracicaba. pp. 731-754.

Scheneiter, O. and Rimieri, P. 2001. Herbage accumulation, tiller population density, and sward components of prairie grass under different nitrogen levels. J. Agr. Res., 44: 13-22.

Stobbs, T.H. 1975. The effect of plant structure on the intake nitrogen on the size of bite harvested by Jerssey cows grazing Setaria anceps cv. Kazungula swards. Aus. J. Agr. Res., 24: 9971007.

Taiz, L., Zeiger, E. 1991. Plant physiology. The Benjamim/Cummings Publishing Company, Inc. Redwood City. California.

Tieszen, L.L. and Detling, J.K. 1983. Productivity of grassland and tundra. In: Lange, O.L., Nobel, P.S., Osmond, C.B., Ziegelere, H. (Eds.). Encyclopedia of plant physiology. Ecosystem processes: mineral cycling, productivity and man's influence. Springer-Verlag. Berlin. Vol. 12 D. pp. 173-203.

Varlet-Grancher, C., Gosse, G., Chartier, M., Sinoquet, H., Bonhomme, R. and Allirand, J.M. 1989. Mise au point: rayonnement solaire absorbé ou intercepté par un couvert végétal. 


\section{VIEIRA E MOCHEL FILHO}

Agronomie, 9: 419-439.

Van Loo, E. N. 1992. Tillering, leaf expansion and growth of plants of two cultivars of perennial ryegrass grown using hydroponics at two water potentials. Ann. Bot., 70: 511-518.

Van Soest, P.J. 1994. Nutritional ecology of the ruminant. Comstock Publishing. New York.
$476 \mathrm{pp}$.

Whitheman, P.C. 1980. Tropical pasture science. Oxford University Press. New York. 392 pp. Wilson, J.R. 1982. Effects of water stress on herbage quality. In: International grassland congress, 14. Proceedings... Lexington. pp. 470-472. 